\title{
Significance of Medical Care Takers in Maternity Ward
}

\author{
Latha Uppala ${ }^{1^{*}}$ \\ Department of Pharmaceutics, SSJ College of pharmacy, India.
}

Received: November 22, 2017; Accepted: November 25, 2017; Published: November 30, 2017

*Corresponding author: Latha Uppala, Department of Pharmaceutics, SSJ College of pharmacy, India.

\section{Introduction}

Maternity ward is a ward that specializes in caring for women while they are pregnant and during childbirth.

Education requirements for maternity ward medical attendants must be registered nurses and have either a bachelor of science in nursing or a associate degree in nursing from an authorize school they should pass their state's Leading body of Medical caretaker Inspectors permitting exam. Since they work with infants, they should be prepared in neonatal revival and fetal checking.

Medical attendants give maternity ward care to pregnant ladies in doctor's facilities. And furthermore they oversee pregnant ladies through the entire period of their pregnancy. Identify work indications in ladies and give suitable care. Convenient Checking of cervix widening and include compression to identify pregnancy ladies, Screen indispensable signs like circulatory strain and heartbeat rate in pregnancy ladies. Check child's condition while in labor utilizing fetal screen or Doppler. Help and bolster gynecologists or counseling doctors in treating pregnant ladies. Help and bolster obstetricians in treating infants on the off chance that they are sick. The treatment is arranged exclusively in co-task with obstetricians and birthing specialists: the reason for existing is to assurance the wealth of the mother and baby.

A brief, physical examination is also performed to check for obvious signs that the baby is healthy. Other necessary procedures will be done over the next few minutes and hours. These may be done in the delivery room or in the nursery, depending on the hospital policy and the condition of the baby

\section{References}

1. Ellie Williams. Labor Room Nurses vs. Postpartum Nurses. chron. 2018;

2. Maternity hospital. Wikipedia. 2016

3. Hospital care during pregnancy. HUS. 